\title{
On the anti-correlation between COVID-19 infection rate and natural UV light in the UK
}

\author{
Arnon Blum ${ }^{1}$, Constantina Nicolaou ${ }^{2}$, Ben Henghes ${ }^{2}$, and Ofer Lahav ${ }^{2 *}$ \\ ${ }^{1}$ Baruch Padeh Medical Center, Azrieli Faculty of Medicine in the Galilee, Bar \\ Ilan University, Israel \\ ${ }^{2}$ Department of Physics \& Astronomy, University College London, Gower \\ Street, London, WC1E 6BT, UK \\ *e-mail: o.lahav@ucl.ac.uk
}

28 November 2020

NOTE: This preprint reports new research that has not been certified by peer review and should not be used to guide clinical practice.

\begin{abstract}
While it is well established that the rate of COVID-19 infections can be suppressed by social distancing, environmental effects may also affect the infection rate. Here we consider the hypothesis that natural Ultra-Violet (UV) light (UVA and UVB) is reducing COVID-19 infections by enhancing human immunity through vitamin-D and/or by suppressing the virus itself. We focus on the United Kingdom (UK), by examining daily COVID-19 infections (F) and UV Index (UVI) data over the period March to October 2020. We find an intriguing empirical anti-correlation between $\log _{10}(\mathrm{~F})$ and $\log _{10}(\mathrm{UVI})$ with a correlation coefficient of -0.933 over the period from 11 May (when the first UK lockdown ended) to 28 October 2020. The anticorrelation may reflect causation with other factors which are correlated with the UVI. Either way, UVI should be included in modelling the pattern of COVID-19 infections and deaths. We started quantifying such correlations in other countries and regions.
\end{abstract}

\section{Introduction}

Our hypothesis is that natural UV light suppresses the spread of COVID-19 virus in at least two ways: the effect on the virus itself, and on the human skin. We note that while natural UV may cause skin cancer, it generates vitamin-D which supports the immune system.

There are three types of solar UV radiation classified according to their wavelength. UVC is a short wavelength $(100-280 \mathrm{~nm})$ radiation and it is the most damaging to the human body. However, it is completely filtered by the atmosphere and does not reach the Earth's surface. It is well known that UVC produced in the lab is used to inhibit viruses. UVB is a medium 
wavelength $(280-315 \mathrm{~nm})$ radiation and most of it is filtered by the atmosphere. UVA is a long wavelength $(315-400 \mathrm{~nm})$ radiation and accounts for about $95 \%$ of the UV radiation reaching the Earth's surface. The UV Index (UVI) is a measure of the strength of sunburn-producing UV radiation at a particular place and time. Typical values of UVI in the UK range between 0 and 8.

The possible correlation between UV light and COVID-19 has been discussed in the literature, with contradictory conclusions. One study [1] found no association of COVID-19 transmission with UV radiation in Chinese cities. Others [2] found modest impact of UV light and other environmental effects on the reduction of COVID-19 transmission. Another study [3] pointed out that UV radiation will not be effective in places with high air pollution, where UV light turns into heat. On the other hand, other studies [4-6] have found that UV light is associated with decreased COVID-19 growth rate. Given the disagreement on the impact of UV light on COVID-19 transmission we take a fresh look at data for the UK. Our study is also strongly motivated by the second wave of COVID-19 in many Northern hemisphere countries during their winter.

\section{Background on the impact of UV}

Most of the respiratory viral infections have a seasonal pattern, that may be related to climate changes, humidity and UV irradiation from the sun, latitude, air pollution, height, and the human nature (genetic and epigenetic factors and behavioural characteristics). Enveloped viruses have a cold temperature preference (influenza A and B) [7]. A study examined the climate of 50 cities that were affected with the COVID-19 found that 8 cities had high morbidity and mortality rates. All 8 cities were located between latitudes $30^{\circ} \mathrm{N}$ and $50^{\circ} \mathrm{N}$, with a temperature between $5^{\circ} \mathrm{C}$ to $11^{\circ} \mathrm{C}$, and low humidity. Countries located below latitude $35^{\circ} \mathrm{N}$ had lower COVID-19 mortality rates. Countries located above $35^{\circ} \mathrm{N}$ have insufficient sunlight necessary for vitamin D activation. Vitamin D deficiency was found to correlate with hypertension, diabetes mellitus, and obesity, and associated with increased mortality rates [8-11].

Countries that suffered the highest mortality are known to have a high prevalence of vitamin D deficiency (Italy, Spain, UK, France). In Nordic countries, where sunlight is limited, vitamin $\mathrm{D}$ food fortification is mandatory and the mortality rate was lower in the recent pandemic [12]. Milan latitude is $45^{\circ} \mathrm{N}$, and Naples is located at $40^{\circ} \mathrm{N}$. Naples gets 58 more sunny days annually compared with Milan [13]. In Naples the death toll from COVID-19 was 403/million compared with 15,729/million in Milan (a $>39$ fold increase). A study in Scotland found that UVA exposure was inversely associated with myocardial infarction incidence, without any relation to temperature or UVB irradiation [14]. UVA penetrates to the epidermis, reaching blood vessels, keratinocytes and endothelial cells [15].

Sunlight activates Nitric Oxide (NO) in the skin. NO is a potent modulator of the cardiovascular system, reducing blood pressure and peripheral resistance [16-18]. NO is a signalling molecule responsible for the hoemostasis of blood vessels, affects cellular proliferation, inflammatory processes, and has an anti-bacterial and anti-viral activity [19-21]. Usually NO is produced in endothelial cells by oxidation of L-arginine to NO and citrulline. However, inducible NOS (i-NOS) is calcium-independent, activated during stress conditions like acute or chronic inflammation or infection [22-25]. NO inhibited the replication of SARS-CoV by inhibiting fusion between the S protein and its receptor, the angiotensin converting enzyme to receptor and through inhibition of viral RNA replication [26].

UVA penetrates into the dermal layer through the keratinocytes to the fibroblasts and the 
medRxiv preprint doi: https://doi.org/10.1101/2020.11.28.20240242; this version posted November 30, 2020. The copyright holder for this preprint (which was not certified by peer review) is the author/funder, who has granted medRxiv a license to display the preprint in It is made available under a CC-BY-NC-ND 4.0 International license .

microvascular endothelial cells [27]. Keratinocytes, Langerhans cells, dermal fibroblasts, and melanocytes - all these cells have the ability to induce i-NOS once these cells were activated by cytokines [28].

\section{Results}

In our study we focus on the UK, using COVID-19 data [29], and UVI data for London [30]. Although the UVI is for London, the variations in different places in the UK are within 0.8 UVI. Stringency index represents the lockdown measures taken in the UK and defined in [31]. Figure 1 shows the daily infections and deaths for the UK along with the UVI and stringency index for the period 22 January to 28 October 2020. We see visually strong anti-correlation between daily infections and UVI.

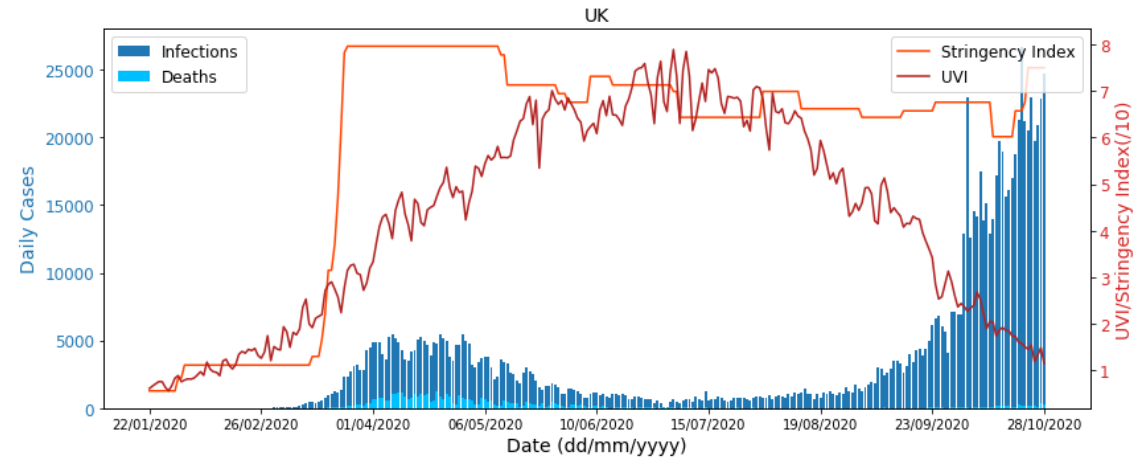

Figure 1: Daily infections (dark blue) and deaths (light blue) along with the stringency index (orange) and UVI (red) for the period 22 January up to 28 October 2020 for the UK. As expected, the UVI increased from January to July when it reached a peak and then dropped. From January to April while the UVI increased, the number of infections went up too. The UK government lockdown started on 23 March and this resulted in a decrease in infections due to social distancing. The lockdown was relaxed on 11 May. However, increase in the UVI over the period 23 March to 1 July might have helped as well to decrease the number of infections. Over the period 2 July to 28 October the increase in infections is strongly anti-correlated with UVI, as we quantify in Table 1.

To quantify the correlation seen in Figure 1 we consider the correlation coefficient between $\mathrm{X}$ and $\mathrm{Y}$, defined as

$$
\rho=\frac{\left\langle\left(X-\mu_{X}\right)\left(Y-\mu_{Y}\right)\right\rangle}{\sigma_{X} \sigma_{Y}},
$$

where $\mu$ represents the mean and $\sigma$ the standard deviation. We applied this to $X=\log _{10}(U V I)$ and $Y=\log _{10}(F)$. We find the correlation coefficient averaged over the period 23 March (day that the first lockdown was imposed in the UK) to 28 October 2020 to be $\rho=-0.889$ suggesting an anti-correlation with a p-value of $2.480 \times 10^{-75}$, implying that the null hypothesis of no correlation is strongly ruled out. Additionally, we calculate the correlation coefficient for the period 11 May (when initial relaxations of lockdown began) until the 28 October 2020 and find this to be $\rho=-0.933$ with a p-value of $4.873 \times 10^{-76}$. Over this period the stringency index was roughly constant to within $13 \%$, so variations due to this factor were probably limited. ${ }^{1}$

\footnotetext{
${ }^{1}$ We note that we identified two outliers in the number of daily infections which resulted from merging pillars of reported cases on the 1 and 2 July and hence were removed from the analysis.
} 
medRxiv preprint doi: https://doi.org/10.1101/2020.11.28.20240242; this version posted November 30, 2020. The copyright holder for this preprint (which was not certified by peer review) is the author/funder, who has granted medRxiv a license to display the preprint in It is made available under a CC-BY-NC-ND 4.0 International license .

The correlation coefficient $\rho$ for different date ranges and time lags of 7 and 14 days is shown in Table 1. Time lag makes small difference to $\rho$, probably as competing effects wash out a particular time lag. In Figure 2, the top panel shows the daily infections and UVI and on the bottom panel we plot the rolling correlation coefficient between $\log _{10}(U V I)$ and $\log _{10}(F)$ with a window size of 50 days. We observe a negative correlation between the infections and UVI from mid-April onwards.

\begin{tabular}{|c|c|c|c|}
\hline \multirow{2}{*}{ Date Range } & \multicolumn{3}{|c|}{ Corr. Coef. $\rho$ of $\log _{10}(\mathbf{U V I}) \& \log _{10}(\mathbf{F})$} \\
\cline { 2 - 4 } & No lag & 7 day lag & 14 day lag \\
\hline 23 Mar 20 - 28 Oct 20 & -0.889 & -0.895 & -0.836 \\
11 May 20 - 28 Oct 20 & -0.933 & -0.944 & -0.934 \\
23 Mar 20 - 01 Jul 20 & -0.699 & -0.705 & -0.695 \\
02 Jul 20 - 28 Oct 20 & -0.964 & -0.958 & -0.943 \\
\hline
\end{tabular}

Table 1: The correlation coefficient $\rho$ defined in Eq. 1 for different time intervals and time lags. Our logic in the selecting these time intervals is as follows: the first UK lockdown was between 23 March and 11 May 2020, and a second lockdown started a week after 28 October 2020. The minimum number of infections happened on approximately on 1 July, so the 3rd and 4th entries at the table characterise what happened in the decline and rise phases of the infections. Formal bootstrap error bars on $\rho$ are less than 0.05 .
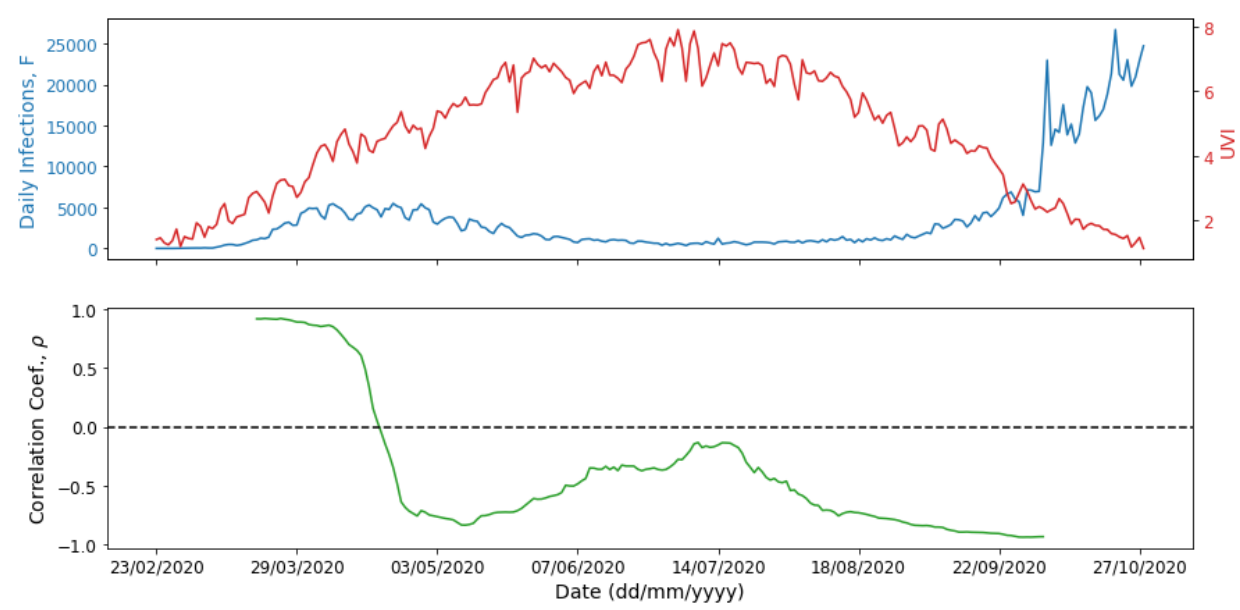

Figure 2: Top panel shows the daily infections (blue) and UVI (red) for the UK from the 23 February until the 28 October. In the bottom panel we plot the rolling correlation coefficient of $\log _{10}(\mathrm{~F})$ and $\log _{10}(\mathrm{UVI})$ (green) with a window size of 50 days.

Figure 3 shows a log-log scatter diagram of $F$ vs. UVI, with colour coding for time intervals. The nearly linear correlation is remarkable. We fit the data to

$$
\log _{10}(F)=m \log _{10}(U V I)+c,
$$

using standard least squares linear regression. For the period 23 March to 28 October we find 


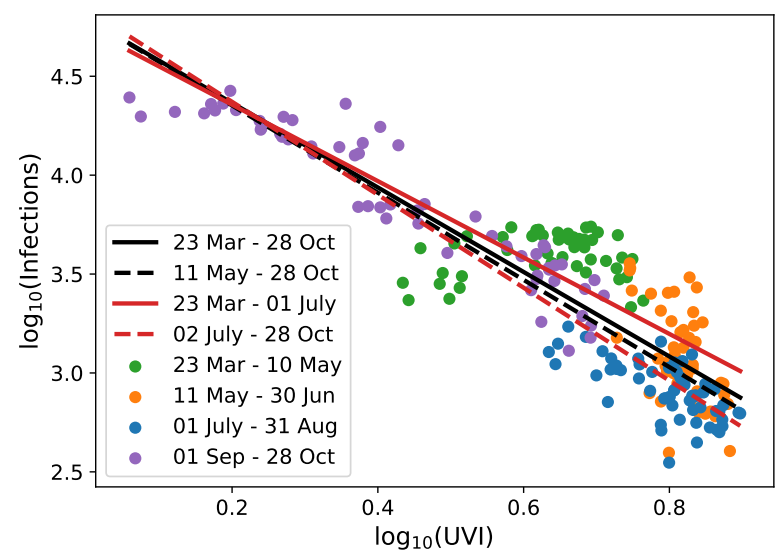

Figure 3: Log-log scatter diagram of F against UVI with colour-coded time intervals. The solid black line shows a fit by linear regression (Eq. 2) for the period 23 March to 28 October 2020 and the black dashed line for the period 11 May to 28 October 2020. The solid red line represents the first peak and decline phase of the infections and the dashed red line the rise phase of the second peak.

find $m=-2.136_{-0.051}^{+0.069}$ and $c=4.792_{-0.041}^{+0.042}$ where the $68 \%$ CL were derived using Bootstrapping [32]. The other three fits shown in Figure 3 are within 10\% for the slope and $1 \%$ for the intercept.

\section{Discussion}

In conclusion, we have found an intriguing empirical correlation between the daily UVI and COVID-19 infections in the UK, with a correlation coefficient of -0.933 between 11 May and 28 October 2020. We are in the process of extending our analysis for other countries and regions. For now we shall only mention the example of Chile, as a Southern Hemisphere case. Over the periods of rise (25 March to 6 June 2020) and fall (7 June to 28 October 2020) in infections we find an anti-correlation of $\rho=-0.907$ and $\rho=-0.730$ respectively, in accord with the anti-correlation we found for the UK. Another important test would be to contrast countries with the same environmental effects but different lockdown policies, for example Norway and Sweden.

We note that a correlation between two observables does not necessarily mean causation. If the UV light directly affects the level of infections it could be either by reducing the survival of the virus itself or by improving the immunity of people via the production of Vitamin-D and possibly a combination of the two. On the other hand, the UVI may indicate other causes. For example, low UVI may imply that people spend more time with other people indoors (e.g. at home or in shops) or suffer from other winter-time diseases, increasing the chance for infection. Other possible variables are population density, temperature, humidity, air pollution and other geographical parameters.

We emphasise that the infection by COVID-19 is a multi-parameter problem. There is indeed strong empirical evidence that keeping social distancing and wearing masks are the significant factors in reducing the transmission. It is also clear that the optimal solution to the infection would be via a vaccine. But in any case we advocate including the impact of the UV in the modelling of COVID-19 spread and in proposed medical protocols. 
medRxiv preprint doi: https://doi.org/10.1101/2020.11.28.20240242; this version posted November 30, 2020. The copyright holder for this preprint (which was not certified by peer review) is the author/funder, who has granted medRxiv a license to display the preprint in

It is made available under a CC-BY-NC-ND 4.0 International license .

\section{Data availability}

We use publicly available data from JHU on COVID-19 and from TEMIS on UVI.

\section{Code availability}

We plan to make the code available at a later stage.

\section{References}

1. Yao, Y. et al. No association of COVID-19 transmission with temperature or UV radiation in Chinese cities. European Respiratory Journal 55. ISSN: 0903-1936. eprint: https ://erj . ersjournals. com/content/55/5/2000517. full.pdf (2020).

2. Xu, R. et al. The Modest Impact of Weather and Air Pollution on COVID-19 Transmission. medRxiv. eprint: https : //www . medrxiv . org/content/early/2020/05/24/2020 . 05 . 05.20092627.full.pdf (2020).

3. Yudistira, N., Sumitro, S. B., Nahas, A. \& Riama, N. F. UV light influences covid-19 activity through big data: trade offs between northern subtropical, tropical, and southern subtropical countries. medRxiv. eprint: https : / / www . medrxiv . org/content/early / 2020/05/22/2020.04.30.20086983.full.pdf (2020).

4. Merow, C. \& Urban, M. C. Seasonality and uncertainty in global COVID-19 growth rates. Proceedings of the National Academy of Sciences. ISSN: 0027-8424 (2020).

5. Nicastro, F. et al. Modulation of COVID-19 Epidemiology by UV-B and -A Photons from the Sun. medRxiv. eprint: https : / www . medrxiv . org/content/early/2020/07/28/ 2020.06.03.20121392.full.pdf (2020).

6. Cherrie, M. et al. Ultraviolet A Radiation and COVID-19 Deaths: A Multi Country Study. medRxiv. eprint: https : //www . medrxiv . org/content/early/2020/08/01/2020.07. 03.20145912.full.pdf (2020).

7. Price, R. H. M., Graham, C. \& Ramalingam, S. Association between viral seasonality and meteorological factors. English. Scientific Reports 9. ISSN: 2045-2322 (2019).

8. Kunutsor, S. K., Apekey, T. A. \& Steur, M. Vitamin D and risk of future hypertension: meta-analysis of 283,537 participants. European Journal Of Epidemiology 28, 205-221. ISSN: 0393-2990 (2013).

9. Mauss, D., Jarczok, M. N., Hoffmann, K., Thomas, G. N. \& Fischer, J. E. Association of Vitamin D Levels with Type 2 Diabetes in Older Working Adults. International Journal Of Medical Sciences 12, 362-368. ISSN: 1449-1907 (2015).

10. Yao, Y. et al. A meta-analysis of the relationship between vitamin D deficiency and obesity. International Journal Of Clinical And Experimental Medicine 8, 14977-14984. ISSN: 19405901 (2015).

11. Herrick, K. A. et al. Vitamin D status in the United States, 2011-2014. American Journal Of Clinical Nutrition 110, 150-157. Issn: 0002-9165 (2019).

12. Lips, P. et al. Current vitamin D status in European and Middle East countries and strategies to prevent vitamin D deficiency: a position statement of the European Calcified Tissue Society. European Journal Of Endocrinology 180, P23-P54. ISSN: 0804-4643 (2019). 
13. Whittemore, P. B. COVID-19 fatalities, latitude, sunlight, and vitamin D. American Journal Of Infection Control 48, 1042-1044. ISSN: 0196-6553 (2020).

14. Mackay, D. F. et al. UVA and Seasonal Patterning of 56370 Myocardial Infarctions Across Scotland, 2000-2011. Journal Of The American Heart Association 8. ISSN: 2047-9980 (2019).

15. Holick, M. F. Biological Effects of Sunlight, Ultraviolet Radiation, Visible Light, Infrared Radiation and Vitamin D for Health. English. Anticancer Research 36, 1345-1356. ISSN: 0250-7005 (2016).

16. Weller, R. B. The health benefits of UV radiation exposure through vitamin D production or non-vitamin D pathways. Blood pressure and cardiovascular disease. Photochemical \& Photobiological Sciences 16, 374-380. ISSN: 1474-905X (2017).

17. Liu, D. et al. UVA Irradiation of Human Skin Vasodilates Arterial Vasculature and Lowers Blood Pressure Independently of Nitric Oxide Synthase. Journal Of Investigative Dermatology 134, 1839-1846. ISSN: 0022-202X (2014).

18. Oplaender, C. et al. Whole Body UVA Irradiation Lowers Systemic Blood Pressure by Release of Nitric Oxide From Intracutaneous Photolabile Nitric Oxide Derivates. Circulation Research 105, 1031-U215. ISSN: 0009-7330 (2009).

19. Pope, M. et al. Resistance to murine hepatitis virus strain 3 is dependent on production of nitric oxide. Journal Of Virology 72, 7084-7090. ISSN: 0022-538X (1998).

20. Adler, H. et al. Suppression of Herpes simplex virus type 1 (HSV-1)-induced pneumonia in mice by inhibition of inducible nitric oxide synthase (iNOS, NOS2). Journal Of Experimental Medicine 185. AAAAI/AAI/CIS Joint Meeting, SAN FRANCISCO, CA, FEB 21-26, 1997, 1533-1540. ISSN: 0022-1007 (1997).

21. Lane, T., Paoletti, A. \& Buchmeier, M. Disassociation between the in vitro and in vivo effects of nitric oxide on a neurotropic murine coronavirus. Journal Of Virology 71, 22022210. ISSN: 0022-538X (1997).

22. Akaike, T. et al. Pathogenesis of influenza virus-induced pneumonia: Involvement of both nitric oxide and oxygen radicals. Proceedings Of The National Academy Of Sciences Of The United States Of America 93, 2448-2453. ISSN: 0027-8424 (1996).

23. Coleman, J. Nitric oxide in immunity and inflammation. International Immunopharmacology 1, 1397-1406. ISSN: 1567-5769 (2001).

24. Poljakovic, M., Karpman, D., Svanborg, C. \& Persson, K. Human renal epithelial cells express iNOS in response to cytokines but not bacteria. Kidney International 61, 444455. ISSN: 0085-2538 (2002).

25. Saxena, S., Mathur, A. \& Srivastava, R. Induction of nitric oxide synthase during Japanese encephalitis virus infection: Evidence of protective role. Archives Of Biochemistry And Biophysics 391, 1-7. ISSN: 0003-9861 (2001).

26. Akerstrom, S., Gunalan, V., Keng, C. T., Tan, Y.-J. \& Mirazimi, A. Dual effect of nitric oxide on SARS-CoV replication: Viral RNA production and palmitoylation of the S protein are affected. Virology 395, 1-9. ISSN: 0042-6822 (2009).

27. Holliman, G., Lowe, D., Cohen, H., Felton, S. \& Raj, K. Ultraviolet Radiation-Induced Production of Nitric Oxide: A multi-cell and multi-donor analysis. Scientific Reports 7. ISSN: 2045-2322 (2017). 
medRxiv preprint doi: https://doi.org/10.1101/2020.11.28.20240242; this version posted November 30, 2020. The copyright holder for this preprint (which was not certified by peer review) is the author/funder, who has granted medRxiv a license to display the preprint in

It is made available under a CC-BY-NC-ND 4.0 International license .

28. Kuchel, J., Barnetson, R. \& Halliday, G. Nitric oxide appears to be a mediator of solarsimulated ultraviolet radiation-induced immunosuppression in humans. Journal Of Investigative Dermatology 121, 587-593. ISSN: 0022-202X (2003).

29. Dong, E., Du, H. \& Gardner, L. An interactive web-based dashboard to track COVID-19 in real time. Lancet Inf Dis. 20, 533-534 (5 2020).

30. Van Geffen, J., Van Weele, M., Allaart, M. \& Van der A, R. TEMIS UV index and UV dose operational data products, version 2. Dataset. 2017.

31. Hale, T., Webster, S., Petherick, A., Phillips, T. \& Kira, B. Oxford COVID-19 Government Response Tracker. (2020).

32. Efron, B. Bootstrap Methods: Another Look at the Jackknife. Ann. Statist. 7, 1-26. https://doi.org/10.1214/aos/1176344552 (Jan. 1979).

\section{Acknowledgements}

We thank R. Ellis, R. Lahav, C. La Porta, P. Lemos, D. Pillay, M. Treyer and S. Zapperi for helpful discussions. BH, OL and CN are supported by the STFC UCL Centre for Doctoral Training in Data Intensive Science (grant number ST/P006736/1). (ST/R000476/1).

\section{Author contributions}

$\mathrm{AB}$ has proposed the idea of looking at correlations between the UVI and COVID-19 infections and has contributed to interpretation of results. $\mathrm{CN}$ and $\mathrm{BH}$ have performed the statistical analysis of this work. OL has proposed analysis tools and plots, has contributed to interpretation and has coordinated the team. Each of the four authors have written sections of the paper.

\section{Competing interests}

The authors declare no competing interests. 